\title{
Quantitative Trait Loci Mapping of Multiple Independent Loci for Resistance to Fusarium oxysporum f. sp. vasinfectum Races 1 and 4 in an Interspecific Cotton Population
}

\author{
Congli Wang, Mauricio Ulloa, ${ }^{\dagger}$ Tra Duong, and Philip A. Roberts ${ }^{\dagger}$
}

First, third, and fourth authors: University of California, Riverside, CA 92521; first author: Key Laboratory of Mollisols Agroecology, Northeast Institute of Geography and Agroecology, Chinese Academy of Sciences, Harbin, 150081, China; and second author: USDA-ARS, PA, CSRL, Plant Stress and Germplasm Development Research, Lubbock, TX 79415.

Accepted for publication 19 December 2017.

\begin{abstract}
Fusarium wilt, caused by the soilborne fungal pathogen Fusarium oxysporum f. sp. vasinfectum, is a vascular disease of cotton (Gossypium spp.). F. oxysporum f. sp. vasinfectum race 1 (FOV1) causes major plant injury and yield loss in G. hirsutum cultivars with coinfection with root-knot nematode (Meloidogyne incognita), while F. oxysporum $\mathrm{f}$. sp. vasinfectum race 4 (FOV4) causes plant damage without nematode coinfection in G. hirsutum and in G. barbadense cultivars. Quantitative trait loci (QTL) analysis of the interspecific cross G. barbadense Pima S-7 × G. hirsutum Acala NemX revealed separate multiple loci determining resistance to FOV1 and FOV4, confirming that race specificity occurs in F. oxysporum f. sp. vasinfectum. Based on the area under the disease progress stairs, six

major QTLs on chromosomes (Chrs) 1, 2, 12, 15 (2), and 21 contributing 7 to $15 \%$ to FOV1 resistance and two major QTLs on Chrs 14 and 17 contributing 12 to $33 \%$ to FOV4 resistance were identified. Minor-effect QTLs contributing to resistance to both FOV1 and FOV4 were also identified. These results define and establish a pathosystem of race-specific resistance under polygenic control. This research also validates the importance of previously reported markers and chromosome regions and adds new information for the location of $F$. oxysporum f. sp. vasinfectum resistance genes. Some $\mathrm{F}_{8}$ recombinant inbred lines have resistance to both FOV1 and FOV4 and also to root-knot nematode, providing multiple resistance sources for breeding.
\end{abstract}

Fusarium wilt of cotton (Gossypium spp.), caused by the fungal soilborne pathogen Fusarium oxysporum f. sp. vasinfectum, is widespread and results in substantial crop loss in most of the major cotton-producing areas of the world. Symptoms of infection include vascular discoloration, leaf wilting, plant stunting, and plant death especially at the seedling stage. As part of a disease complex in the presence of root-knot nematodes (Meloidogyne incognita), the incidence, rate of development, and severity of Fusarium wilt in cotton can increase and resistance to $F$. oxysporum $\mathrm{f}$. sp. vasinfectum can be broken (Abawi and Chen 1998; Garber et al. 1979; Wang and Roberts 2006). Molecular characterization of $F$. oxysporum f. sp. vasinfectum isolates distinguished six races (races 1, 2, 3, 4, 6, and 8) worldwide based on alignment of the translation elongation factor- $1 \alpha$ (653 bp + two indels), mitochondrial small subunit rDNA (677 bp + one indel), nitrate reductase (483 bp + one indel), and phosphate permease (586 bp) gene sequences, but found no difference

†Corresponding authors: P. A. Roberts; E-mail: philip.roberts@ucr.edu, and M. Ulloa; E-mail: mauricio.ulloa@ars.usda.gov

Funding: Partial support for this work was provided by grants from Cotton Incorporated to P. A. Roberts and M. Ulloa, the University of California Discovery Grant Program to P. A. Roberts, the USDA-ARS (grant 6208-21000-019-00), the National Science Foundation of China (grants 31471749 and 31772139), and the One Hundred Talent Grant Program, Chinese Academy of Sciences to C. Wang.

Mention of trade names or commercial products in this manuscript is solely for the purpose of providing specific information and does not imply recommendation or endorsement by the USDA. The U.S. Department of Agriculture is an equal opportunity provider and employer.

*The $\boldsymbol{e}$-Xtra logo stands for "electronic extra" and indicates that one supplementary figure and four supplementary tables are published online.

This article is in the public domain and not copyrightable. It may be freely reprinted with customary crediting of the source. The American Phytopathological Society, 2018. between previously named races 4 and 7 and races 3 and 5 (Cianchetta and Davis 2015; Wang et al. 2010a). Four races (races 1, 3, 4, and 8) of $F$. oxysporum f. sp. vasinfectum were reported from California by Kim et al. (2005). Races 1, 3, and 8 are considered mildly virulent and cause little or no wilt symptoms in the absence of root-knot nematodes. Race 1 is widely distributed in the San Joaquin Valley of California and has been the predominant form of $F$. oxysporum $\mathrm{f}$. sp. vasinfectum worldwide (Kim et al. 2005). Race 4 was originally reported from Asia and was first detected in California in 2001 (Armstrong and Armstrong 1960; Kim et al. 2005; Skovgaard et al. 2001). Race 4 has spread to several cotton production areas in the San Joaquin Valley and has caused severe wilt symptoms and economic losses in Pima cotton (G. barbadense L.), and Upland and non-Upland Acala (G. hirsutum L.), even in the absence of nematodes (Hao et al. 2009; Hutmacher et al. 2013; Kim et al. 2005; Ulloa et al. 2006, 2013).

Although race 4 was indistinguishable genetically from race 7 reported in China based on molecular characters (Cianchetta and Davis 2015; Crutcher et al. 2016; Skovgaard et al. 2001; Wang et al. 2010a), pathogenicity tests revealed that race 4 was more pathogenic than race 7 to Pima cottons and that race 7 was more pathogenic than race 4 to Upland cottons (Armstrong and Armstrong 1960). Recently, Ortiz et al. (2017) found one unique Tfol transposon insertion in the $\mathrm{PHO}$ gene of race 4 isolates but not in other $F$. oxysporum f. sp. vasinfectum genotypes, including India race isolates and China race 7 isolates. A highly virulent strain of $F$. oxysporum $\mathrm{f}$. sp. vasinfectum has been reported to cause extensive damage to cotton in Australia in the absence of root-knot nematodes (Davis et al. 1996; Kim et al. 2005; Lopez-Lavalle et al. 2007, 2012). While host-plant resistance is generally considered to be the most effective management strategy for controlling Fusarium wilt, the occurrence and threat of new races or virulent $F$. oxysporum f. sp. vasinfectum strains in the field supports the need for developing cultivars with combined resistance to different races or strains and multiple pathogens. Genetic analysis of Fusarium 
wilt resistance to each race or strain is an important step toward incorporating broad-spectrum resistance into elite cultivars.

In our previous work, a major resistance locus (Fovl) with allele dosage effect contributing resistance to $F$. oxysporum $\mathrm{f}$. $\mathrm{sp}$. vasinfectum race 1 (FOV1) was identified in G. barbadense Pima S-7 through genetic analysis of $\mathrm{F}_{2}$ and $\mathrm{F}_{3}$ interspecific populations with G. hirsutum (Wang and Roberts 2006). Subsequently, the Fov1 locus was mapped to chromosome (Chr) 16 with microsatellite simple sequence repeat (SSR) markers (Ulloa et al. 2011). Additional inheritance analysis and quantitative trait loci (QTL) mapping of an interspecific recombinant inbred line (RIL) population between G. hirsutum TM-1 and G. barbadense Pima 3-79 showed gene interactions of 6 QTLs across five Chrs $(6,8,11,16$, and 19), explaining 8 to $31 \%$ phenotypic variance of FOV1 disease severity and vascular discoloration ratio (Ulloa et al. 2011). Of these, two QTLs were localized on Chr 11 which harbors multiple biotic stress resistance determinants to other soilborne pathogens including root-knot nematode (Gutiérrez et al. 2010; Shen et al. 2006; Ulloa et al. 2010; Wang et al. 2006, 2008, 2012a; Ynturi et al. 2006), reniform nematode (Dighe et al. 2009; Gutiérrez et al. 2011), Fusarium wilt (Ulloa et al. 2011, 2013, 2016), Verticillium wilt (Bolek et al. 2005; Shi et al. 2016), and black root rot (Niu et al. 2008). Ulloa et al. (2013) identified a large-effect QTL located on Chr 14 determining resistance to F. oxysporum f. sp. vasinfectum race 4 (FOV4) in TM-1 or Pima S-6, and other resistance QTLs on Chrs 3, 6, 8, 17, and 25 in segregating populations derived from a range of resistant and susceptible parental

\section{A}
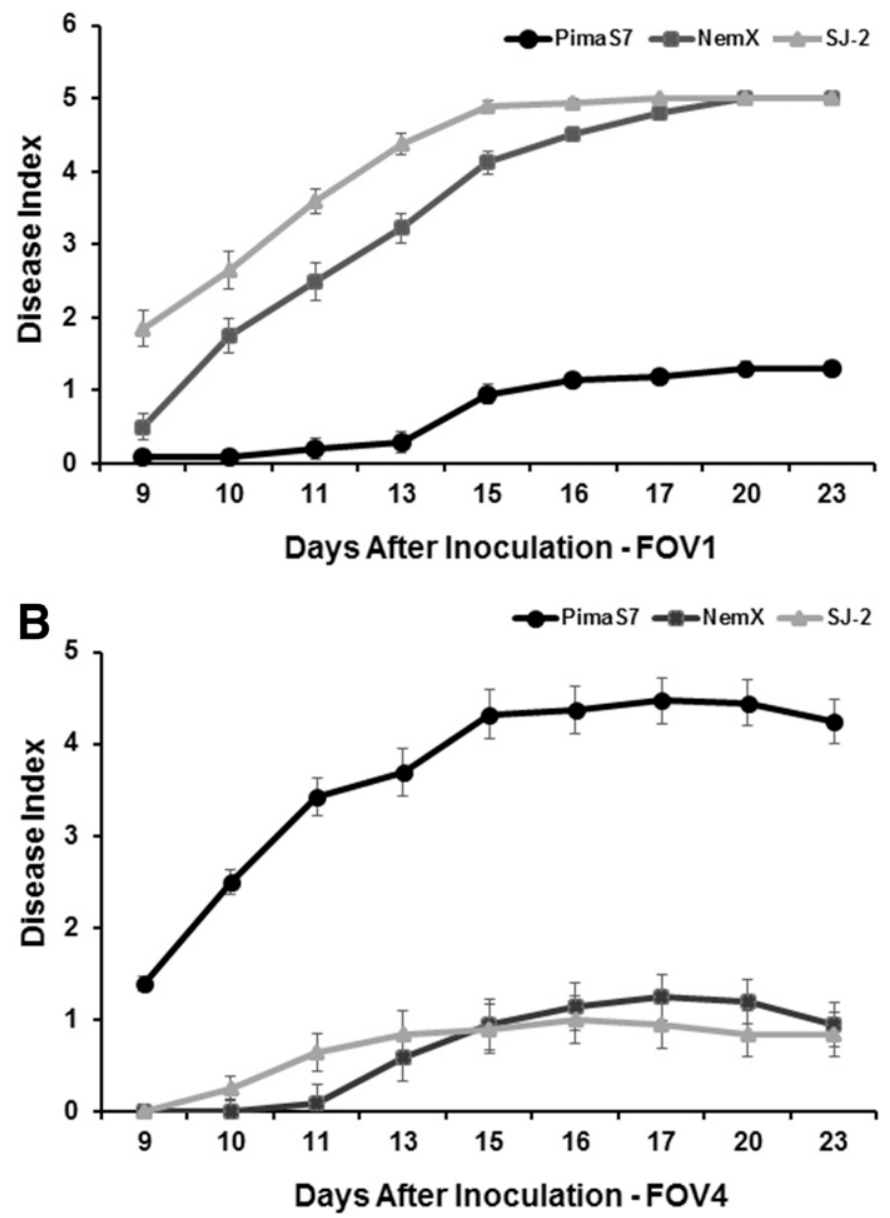

Fig. 1. Progress of wilt disease symptoms of A, Fusarium oxysporum f. sp. vasinfectum race 1 (FOV1) and $\mathbf{B}, F$. oxysporum $\mathrm{f}$. sp. vasinfectum race 4 (FOV4) on three cotton cultivars after inoculation with the root-cut dip inoculation method. Data are the means of 25 replicate plants per treatment. Bars show \pm one standard error. Disease index: 0 to 5 scale $(0=$ no symptoms and 5 = plant death) lines (susceptible G. hirsutum Upland Shorty, two moderately tolerant/ resistant cultivars TM-1 and Acala NemX, resistant G. barbadense Pima S-6, and susceptible Pima S-7, Pima 3-79, and DP744). Ulloa et al. (2016) utilized chromosome substitution lines developed in the G. hirsutum TM-1 background with whole chromosome or chromosome segment substitutions from G. barbadense Pima 3-79 or $G$. tomentosum to identify and confirm a major FOV1 resistance allele from Pima 3-79 on Chr 16 and a major FOV4 resistance locus on Chr 17 from TM-1. Twelve chromosomes $(2,3,7,9,12,15,17$, $18,19,23,24$, and 26 ) were found to link to $F$. oxysporum $\mathrm{f}$. sp. vasinfectum resistance loci in China (Wang et al. 2009, 2010b; Mei et al. 2014). Three QTLs on Chrs 6, 22, and 25 were detected to contribute to Australian Fusarium wilt resistance (Lopez-Lavalle et al. 2012). A partial summary of QTLs associated with F. oxysporum f. sp. vasinfectum resistance also has been made (Wei et al. 2013; Zhang et al. 2015a).

Our aforementioned previous studies indicated that $G$. barbadense Pima S-7 is resistant to FOV1 but susceptible to FOV4, whereas our G. hirsutum Acala NemX genetic source under controlled greenhouse inoculations has shown good levels of tolerance or resistance to FOV4, but has shown susceptibility to FOV1. We developed a $\mathrm{F}_{2^{-}}$ derived $\mathrm{F}_{8}$ RIL segregating population between Pima S-7 and Acala NemX (originally for root-knot nematode resistance mapping). In this study, the $F_{2: 8}$ RIL population was used for QTL mapping of both race 1 and race 4 resistance loci using the knowledge that the two parents have opposite resistance/susceptibility phenotypes to FOV1 and FOV4. The aim of the study was to analyze and confirm the overlap or uniqueness of the race-specific resistance traits, and to determine whether the race-specific resistance is under simple genetic control or is polygenic using this parent/cross combination. The trait-linked markers identified here could be utilized for marker-assisted selection in breeding programs, enabling unique resistance alleles to be pyramided into one genotype or to be deployed individually.

\section{MATERIALS AND METHODS}

Plant material and crosses. Highly inbred genotypes of G. hirsutum 'Acala SJ-2', G. hirsutum 'Acala NemX', and G. barbadense 'Pima S-7' were used in this study. Acala NemX is closely related to Acala SJ-2 which has different responses to root-knot nematode infection and Fusarium wilt infection (Wang and Roberts 2006). An interspecific cross was made between Pima S-7 and Acala NemX, the $F_{1}$ plants were selfed to produce $F_{2}$ and subsequent generations were selfed and advanced by single seed descent to obtain an RIL population. A total of $110 \mathrm{~F}_{2}$ lines and 90 RIL $F_{2: 8}$ families were used for Fusarium wilt screening. All plants for crossing and producing seeds were planted in 15-cm-diameter pots filled with steam-sterilized U.C. Mix \#2 (Baker 1957) soil and grown in a greenhouse. Air temperatures in the greenhouse were maintained between 28 and $35^{\circ} \mathrm{C}$ during the day and $24^{\circ} \mathrm{C}$ at night. Plants in pots were drip-irrigated with fertilizer added to the water.

Fungus inoculum. An isolate of FOV1 from a field in Fresno County, California, and an isolate of $F$. oxysporum $\mathrm{f}$. sp. vasinfectum (CA-14) from a field in the San Joaquin Valley, California, identified as FOV4 (Kim et al. 2005) were provided by S. N. Smith and M. R. Davis, University of California, Davis, CA, respectively. Cultures from single spores were stored on filter paper at $-20^{\circ} \mathrm{C}$. To produce inoculum, the isolates were grown in 9-cm-diameter Petri dishes containing $20 \mathrm{ml}$ of potato dextrose agar (PDA) with $3 \mathrm{mM}$ streptomycin per liter at room temperature for 1 week. Then, 2- to $3-\mathrm{mm}^{2}$ patches of fresh grown culture were cut and put into $500-\mathrm{ml}$ flasks containing potato dextrose liquid medium with $3 \mathrm{mM}$ streptomycin at $28^{\circ} \mathrm{C}$ and shaken at $180 \mathrm{rpm}$ for 3 to 4 days. The conidial suspension was then filtered through eight layers of cheesecloth to remove hyphae, quantified with the aid of a hemacytometer, and diluted with water to obtain $1 \times 10^{6}$ conidia per $\mathrm{ml}$. 
Fusarium wilt assays. A root-cut dip method described by Smith et al. (1994) with modification was performed for the pathogenicity tests (Wang and Roberts 2006). Parents and RILs were germinated in seedling trays for one week, seedlings were uprooted, the roots were rinsed with tap water, trimmed to 2 to $3 \mathrm{~cm}$ length, and immediately dipped for $3 \mathrm{~min}$ into an aqueous suspension of $F$. oxysporum f. sp. vasinfectum inoculum containing $1 \times 10^{6}$ conidia per $\mathrm{ml}$. Seedlings were then transplanted into steamsterilized U.C. Mix \#2 soil (Baker 1957) in pots with five plants per pot. Five pots for each parent and RIL included 20 to 25 plants depending on the availability of seeds. The pots were arranged in a randomized complete block design in the greenhouse. Wilt symptoms started to show at 7 to 9 days after inoculation (DAI), and disease severity was measured starting at 9 (parents and $F_{2}$ ) or 10 (RILs) DAI, providing a series of ratings at 1 to 3 day intervals until 23 DAI. Individual plants were rated for disease severity based on the following index: $0=$ no symptoms; $1=$ epinasty and slight dwarfing; $2=1$ to $30 \%$ of chlorotic leaves; $3=31$ to $80 \%$ of chlorotic leaves and severe stunting; $4=81$ to $100 \%$ of chlorotic leaves; and $5=$ plant death. Multiple evaluations of disease progress were combined into a single value by using the area under the disease progress stairs (AUDPS) (Simko and Piepho 2012). The mathematical formula for AUDPS is

$$
\text { AUDPS }=\sum_{i-1}^{n-1}\left[\frac{\left(y_{i}+y_{i+1}\right)}{2} \times\left(t_{i+1}-t_{i}\right)\right]+\left[\frac{y_{1}+y_{n}}{2} \times \frac{D}{n-1}\right]
$$

where $y_{i}$ is the average disease index at the $i$ th evaluation, $t_{i}$ is time in days at the $i$ th observation, $n$ is the total number of observations $(n=5$ in this study), $y_{1}$ and $y_{n}$ are the average disease indices at the first and last evaluations, respectively, and $D=t_{n}-t_{1}(D=23-10=13$ in this study) (Simko and Piepho 2012). The stems were cut longitudinally and evaluated for vascular discoloration (the ratio of length of vascular discoloration to length of stem $\times 100$ ) at 23 days after inoculation. Data were analyzed using analysis of variance procedure of the SAS statistical software (SAS Institute, Cary, NC). For the purpose of this report, we will use the term resistance to describe the RIL from this population with significant levels of tolerance to FOV4 based on our disease severity index and the ratio of vascular discoloration to plant height.

Marker analysis. Out of 1,200 SSR, 55 polymorphic markers were initially genotyped and used to screen for association with resistance to races FOV1 and FOV4 in the RIL $\mathrm{F}_{2: 8}$ (Pima S-7 $\times$ NemX) population. These 55 markers (BNL, CIR, Gh, MUSB, MUCS, MUSS, and NAU) resided on different chromosomes and were originally identified to be associated to FOV1 and FOV4 resistance in RIL Pima 3-79 $\times$ TM1 population with major and minor effects (Ulloa et al. 2011, 2013). Once potential markers were found linked to $F$. oxysporum $\mathrm{f}$. sp. vasinfectum resistance, more markers adjacent to the area were screened for fine mapping (CMD, https://www.cottongen.org/). A total of 186 primer pairs, with from one to six amplicons per pair, produced 367 SSR polymorphic markers for QTL analysis of Fusarium wilt resistance. In addition, 68 primers (Wang et al. 2017) designed from about 2.2 Mbp of sequence which extended from $58.2 \mathrm{M}$ to $60.4 \mathrm{Mbp}$ on $\mathrm{Chr} 7$ (corresponds to $\mathrm{Chr} 21$ in tetraploid cotton) of the diploid $\mathrm{D}_{5}$ genome (G. raimondii) (Paterson et al. 2012) to fine-map the region of rootknot nematode resistance gene rknl containing markers MUCS088,
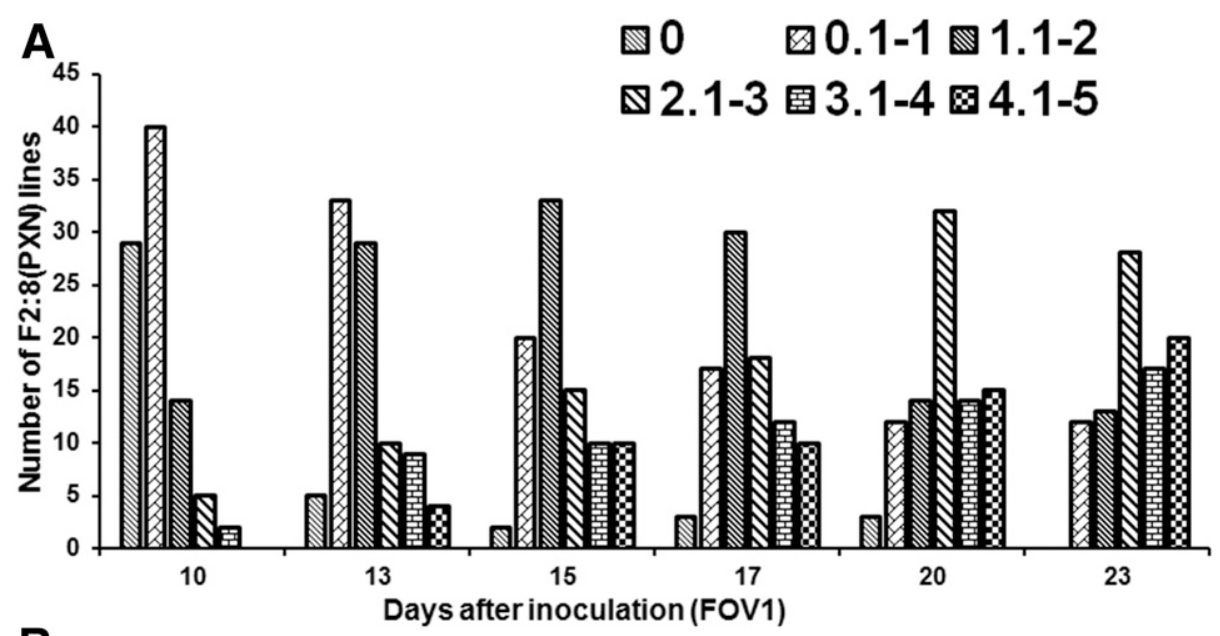

B

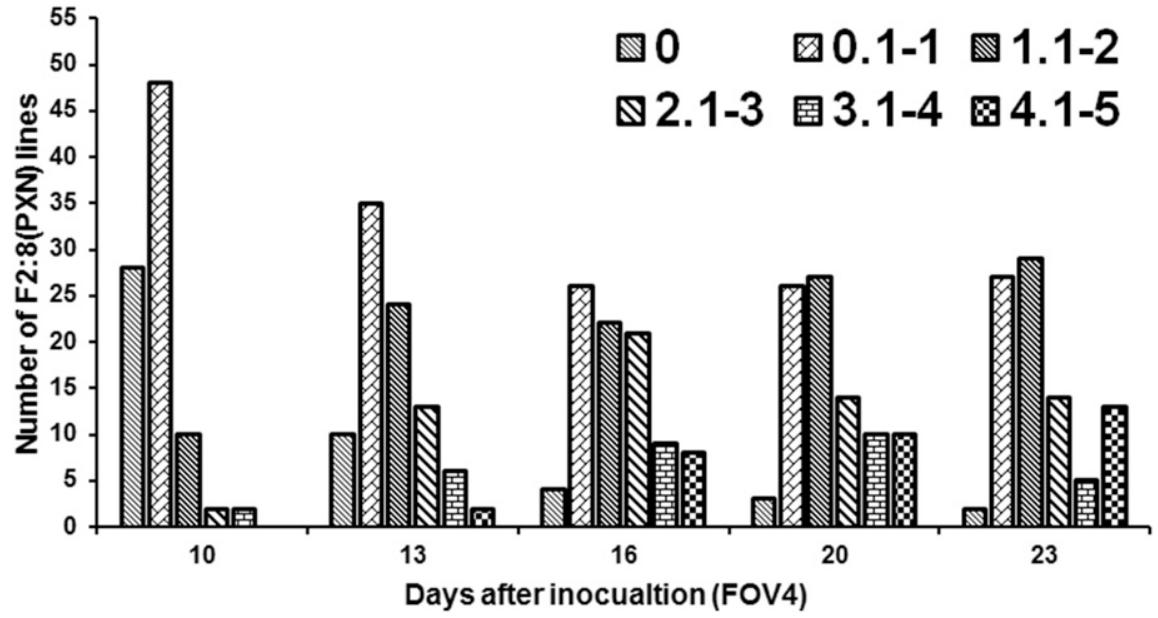

Fig. 2. Phenotypic response of RIL population $\mathrm{F}_{2: 8}($ Pima S-7 $\times$ NemX) to Fusarium oxysporum $\mathrm{f}$. sp. vasinfectum race 1 (A, FOV1) and race 4 (B, FOV4) from 10 to 23 days after inoculation. 
CIR316, and CIR069 (Wang et al. 2006, 2008) were also used for F. oxysporum f. sp. vasinfectum mapping. The primers were named as UCR+ number, such as UCR1 or UCR2. Out of 68 primers, 29 polymorphic markers were identified between Pima S-7 and NemX (Wang et al. 2017). In total, 396 polymorphic markers were used for F. oxysporum f. sp. vasinfectum resistance mapping.

DNA was extracted from fresh or frozen $\left(-80^{\circ} \mathrm{C}\right)$ young cotton leaves from $\mathrm{F}_{2: 7}$ (Pima S-7 $\times$ NemX) plants using the DNeasy Plant Mini kit (Qiagen, Valencia, CA) (Wang et al. 2006). Primers were synthesized by IDT (IDT, Coralville, IA). PCR amplification of cotton molecular markers (Ulloa et al. 2016) was performed on a total volume of $10 \mu \mathrm{l}$ containing $20 \mathrm{ng}$ of DNA template, $1 \times$ PCR buffer, $0.2 \mathrm{mM}$ dNTP (Thermo Scientific, Pittsburgh, PA), 1.25 U of DreamTaq polymerase ( $5 \mathrm{U} / \mu \mathrm{l}$, Thermo Scientific), $0.5 \mu \mathrm{M}$ forward primers synthesized with an M13 forward sequence on the 5 '-end, $0.5 \mu \mathrm{M}$ reverse primer, and $0.025 \mu \mathrm{M}$ IRD labeled M13 primer (700 or 800 channel: CACGACGTTGTAAAACGACLI-COR, Lincoln, NE). PCR was performed as follows: initial denaturing at $95^{\circ} \mathrm{C}$ for $3 \mathrm{~min}$, followed by 35 cycles of $95^{\circ} \mathrm{C}$ for $30 \mathrm{~s}, \mathrm{Tm}-5^{\circ} \mathrm{C}$ for $30 \mathrm{~s}$ (annealing temperature Tm depending on different primers), $72^{\circ} \mathrm{C}$ for $1 \mathrm{~min}$; and the final extension at $72^{\circ} \mathrm{C}$ for $10 \mathrm{~min}$. Denatured DNA fragments were resolved in $25 \mathrm{~cm}$ gels $(0.25 \mathrm{~mm}$ spacer thickness) containing $8 \%$ Long Ranger polyacrylamide gel (Cambrex,

\section{A}

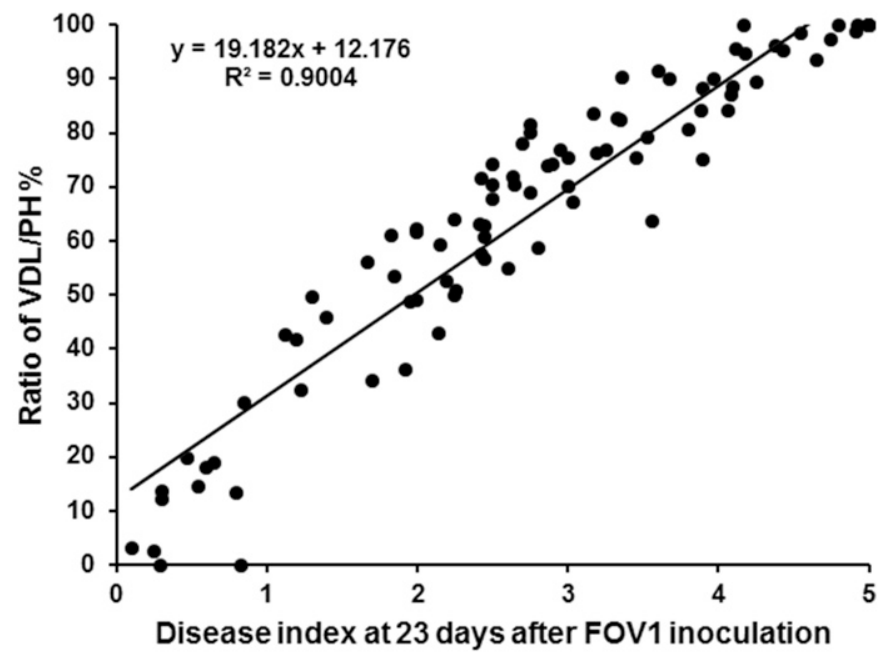

B

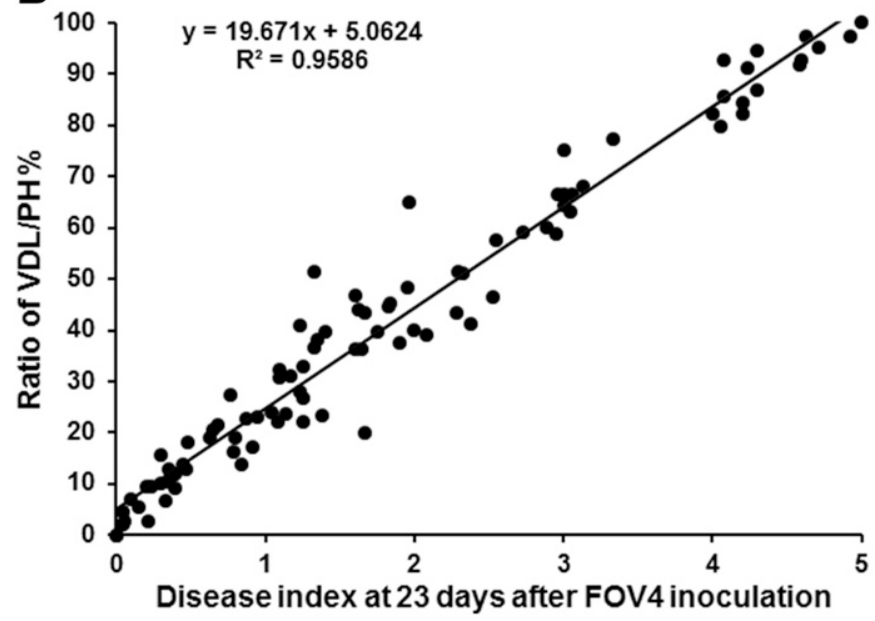

Fig. 3. The correlation of disease index of A, Fusarium oxysporum f. sp. vasinfectum race 1 (FOV1) and $\mathbf{B}, F$. oxysporum f. sp. vasinfectum race 4 (FOV4) with ratio of vascular discoloration to plant height (VDL/PH) in the recombinant inbred line $\mathrm{F}_{2: 8}($ Pima S-7 $\times$ Acala $\mathrm{NemX})$ at 23 days after inoculation.
Rockland, ME). Electrophoresis and detection were performed on a two-dye, model 4000 LI-COR IR ${ }^{2}$ automated sequence (Wang et al. 2006).

Genetic linkage and QTL analysis. The JoinMap version 4.0 computer program (Van Ooijen 2006) was used to develop the linkage groups for chromosomes. Logarithm of odds (LOD) scores of 3 to 15 were examined for each population using the Kosambi mapping function, and a maximum distance of 40 centimorgans (cM) was used to determine linkage between any two markers. The LOD threshold score of $>4.0$ was used to determine linkage between any two markers.

QTL analyses were conducted on AUDPS data with a single calculated value, disease index on different evaluated days, and on the ratio of vascular discoloration to plant height using MapQTL 5.0 (Van Ooijen 2004). Single-marker analysis was conducted by using nonparametric mapping (Kruskal-Wallis analysis [K*]) test equivalent of the one-way analysis of variance. Significant (major) QTLs were set with a more stringent $P<0.005$ for Kruskal-Wallis. Minor effect was set with a $P<0.01,0.05$, or 0.1 for marker-associations which were identified in the P3-79 $\times$ TM1 population. Interval mapping was also conducted based on analysis of pairs of linked markers rather than one marker at a time (such as $\mathrm{K}^{*}$ test). Threshold values for LOD were determined empirically after 1,000 permutation tests for all traits at alpha $=0.05$ (Churchill and Doerge 1994).

\section{RESULTS}

Disease progress of FOV1 and FOV4 in three cotton lines. Wilt disease symptoms caused by FOV1 and FOV4 differed with time after inoculation on the three cotton lines (Pima S-7, Acala NemX, and Acala SJ-2) (Fig. 1A and B). Wilt symptoms appeared on susceptible plants from day 6 after inoculation for both FOV1 and FOV4 tests. Pima S-7 was resistant to FOV1, but susceptible to FOV4 (Fig. 1). Conversely, Acala NemX and Acala SJ-2 were resistant to FOV4 but susceptible to FOV1 under greenhouse conditions (Fig. 1). Acala NemX had less FOV1 wilt symptoms than Acala SJ-2 until 17 DAI, from which time on Acala NemX showed severe symptoms similar to Acala SJ-2 (Fig. 1A). There was no significant difference in response to FOV4 for both Acala NemX and Acala SJ-2 (Fig. 1B).

Phenotypic response of $\mathrm{F}_{2}($ Pima $\mathrm{S}-7 \times \mathrm{NemX})$ population to FOV4. Disease wilt progress of FOV4 on 110 interspecific $\mathrm{F}_{2}($ Pima S-7 $\times$ NemX) lines is shown in Supplementary Figure S1. Transgressive resistance was detected up to 13 DAI compared with wilt symptoms in Acala NemX. From 15 DAI, the disease index was distributed widely indicating multiple genes involved in Fusarium wilt resistance response.

Phenotypic response of RIL $F_{2: 8}($ Pima S-7 $\times$ NemX) population to FOV1 and FOV4. Phenotypic response of 90 interspecific RIL F ${ }_{2: 8}($ Pima S-7 $\times$ NemX) families to FOV1 and FOV4 were evaluated and disease wilt severity over time from inoculation is shown in Figure 2A and B, respectively. Comparing responses to FOV1 and FOV4, the general trend was similar as the number of susceptible families increased with time after inoculation, yet the number of lines for each disease index differed (Fig. 2). At 23 DAI, 25 RIL families had a disease index of 0 to 2 for FOV1, but 58 lines for FOV4, indicating more severe damage caused by FOV1 than by FOV4 in the RIL population. The high correlation of disease index with ratio of vascular discoloration to plant height (VDL/PH) at 23 DAI is presented in Figure 3A for FOV1 (0.90) and Figure 3B for FOV4 (0.96). The AUDPS values among 90 RILs ranged from 0.38 to 91.11 for FOV1 (mean $33.32 \pm$ SE 2.34) and 0 to 91.42 for FOV4 (mean 21.37 \pm SE 2.25).

QTL mapping of FOV1 and FOV4. Using the 396 polymorphic SSR marker screening, linkage groups/maps associated with FOV1 (Fig. 4) and FOV4 (Fig. 5) resistance were developed. Major QTLs $(P<0.005)$ associated with resistance based on AUDPS and vascular discoloration ratio phenotypes are given in Table 1 (FOV1) and 
Table 2 (FOV4). Major and minor QTLs associated with resistance at different times after inoculation are presented in Supplementary Tables S1A and S1B for FOV1 and Supplementary Tables S2A and $\mathrm{S} 2 \mathrm{~B}$ for FOV4. The QTL mapping results based on the analysis of
AUDPS with the combined data and analysis of multiple time points data were similar. Six major QTLs on Chrs 1, 2, 12, 15 (2), and 21 were identified to contribute to FOV1 resistance (Table 1). Of these QTLs, one major effect QTL present in Pima S-7 linked to
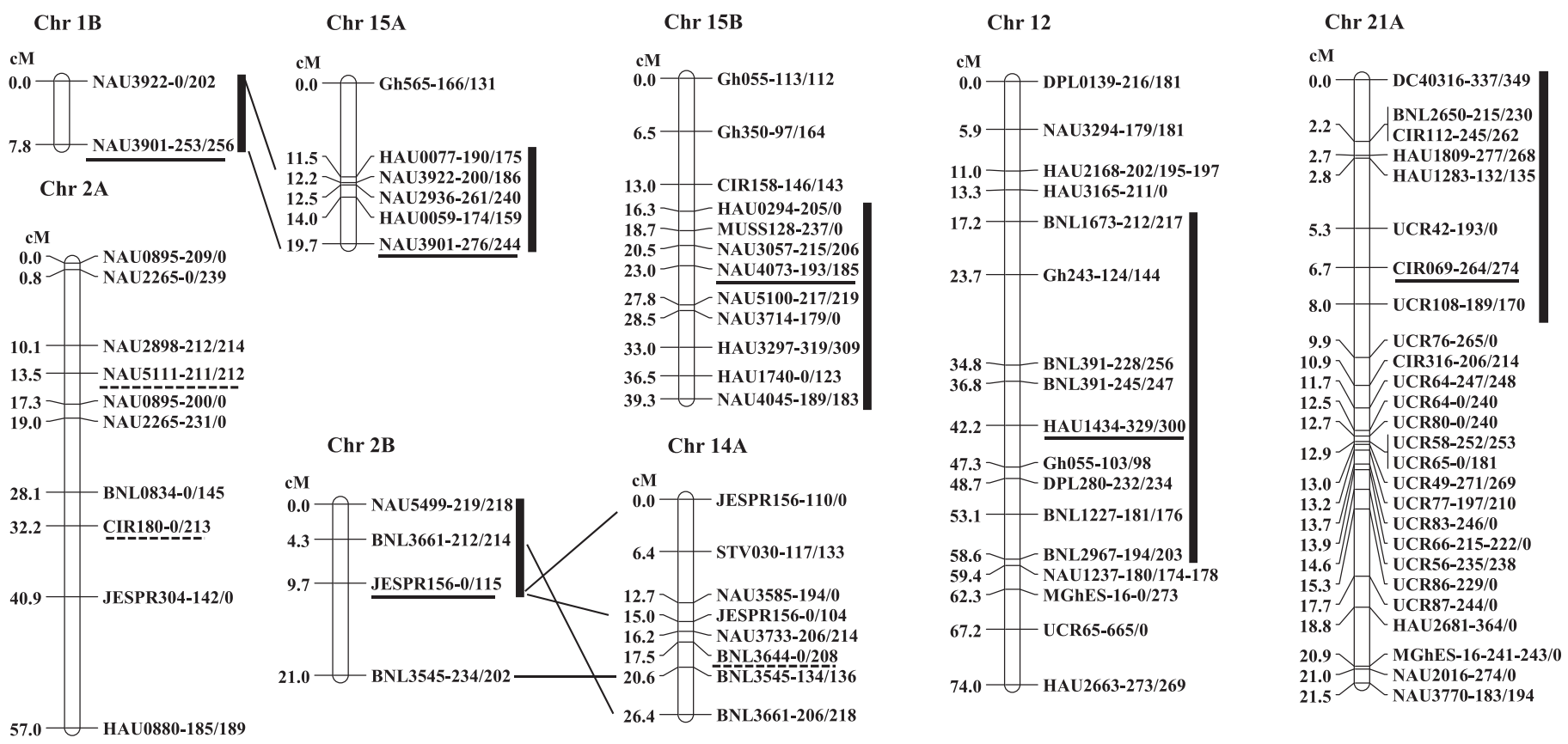

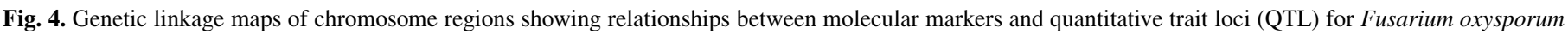

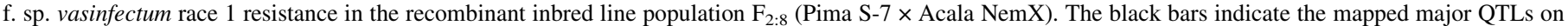

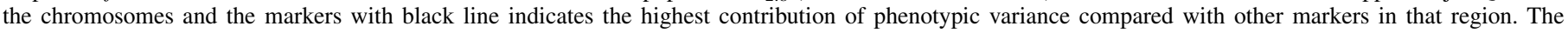
markers with black dashed lines and no black bars indicates minor effect of QTLs on that chromosome.

Chr 17

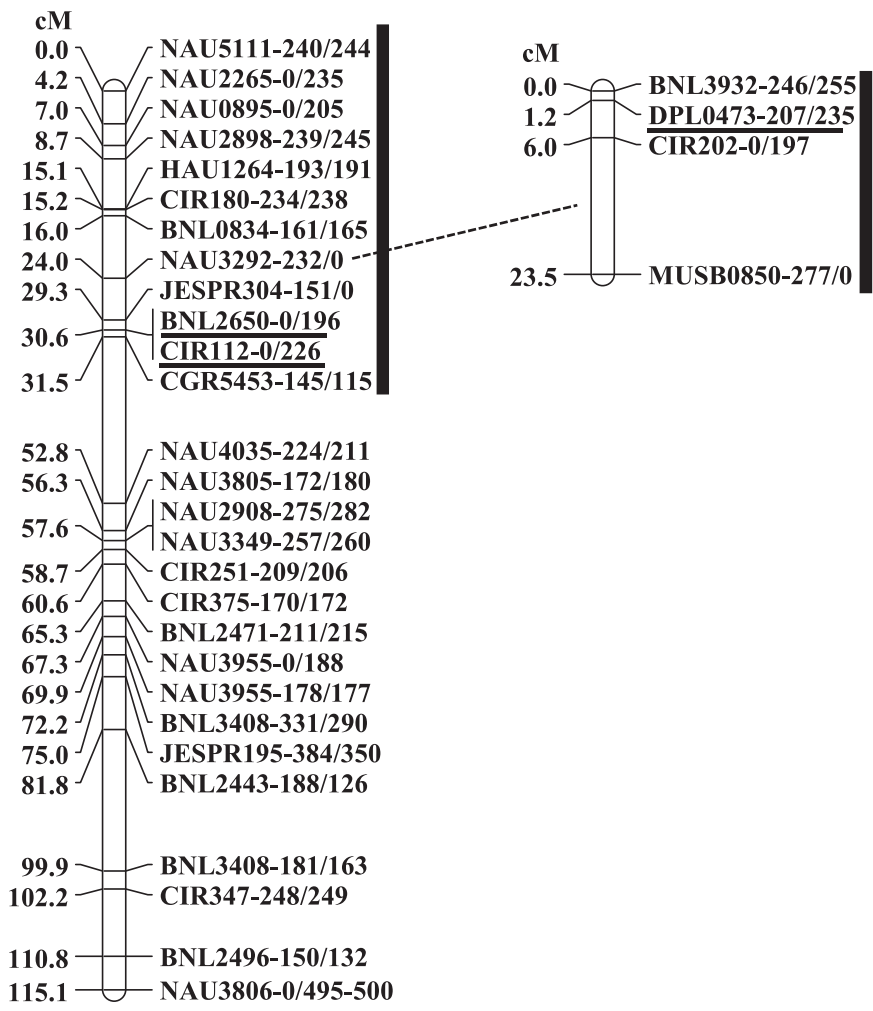

Chr 8

Chr 24

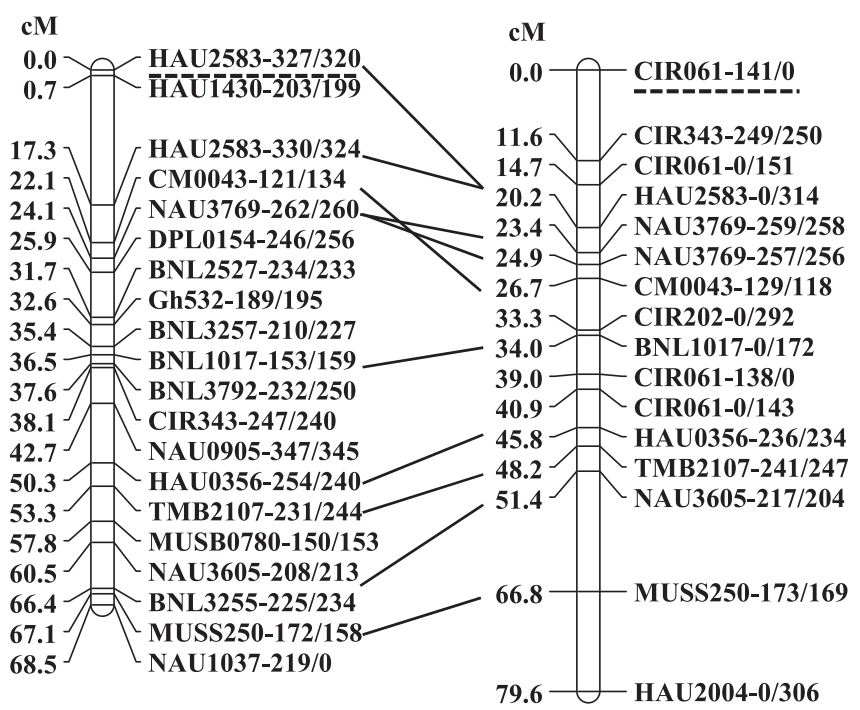

Fig. 5. Genetic linkage maps of chromosome regions showing relationships between molecular markers and quantitative trait loci (QTL) for Fusarium oxysporum f. sp. vasinfectum race 4 in the recombinant inbred line population $\mathrm{F}_{2: 8}$ (Pima S-7 $\times$ Acala NemX). The black bars indicate the mapped major QTLs on the chromosomes and the markers with black line indicates the highest contribution of phenotypic variance compared with other markers in that region. The markers with black dashed lines and no black bars indicates minor effect of QTLs on that chromosome. 
SSR marker HAU1434-329/300 on Chr 12 contributed $15.2 \%$ of phenotypic variance (LOD score $=3.2$ ) in FOV1 resistance with the combined AUDPS value based on interval mapping. QTLs on Chr 1 and its homeologous region on Chr 15 contributed additive effects (7.10 to 7.19) for AUDPS on the combined data and 6.4 to 6.8 for VDL/PH ratio at 23 DAI based on interval mapping.

One major locus with additive effect on FOV4 resistance phenotype from the Acala NemX allele was identified on Chr 17 closely linked to two SSR markers (BNL2650-0/196, CIR112-0/226) (Table 2; Fig. 5). This locus accounted for $33.3 \%$ resistance response (LOD score = 7.91) to FOV4 with AUDPS. One marker BNL0834 mapped to Chr 14 close to BNL3932 (Ulloa et al. 2013; Yu et al. 2012) and associated with FOV4 resistance in TM-1 or Pima S-6 was mapped to Chr 17 in the RIL population Pima S-7 $\times$ Acala NemX (Fig. 5). The region on Chr 14 containing markers BNL3932, DPL0473, CIR202, and MUSB0850 homeologous with Chr 17 accounted for 9.8 to $14.8 \%$ of resistance response to FOV4 with additive effect (6.50 to 7.23) measured by combined AUDPS data and 9.1 to 16.0 for vascular discoloration ratio at 23 DAI based on interval mapping. Ten and twelve minor QTLs contributing resistance to FOV1 and FOV4, respectively, were identified both with the combined AUDPS value and at different time-points after inoculation. Two minor loci were identified on Chr 8 and its homeologous Chr 24 (Fig. 5) contributing up to $8 \%$ of FOV4 resistance phenotype with additive effect. The QTLs from Pima S-7 and Acala NemX contributing to the resistance phenotype to both FOV1 and FOV4 are provided in Table 3.

\section{DISCUSSION}

This study took advantage of analyzing late generation progeny in a new recombinant inbred population generated from an interspecific cotton cross in which the parents were differentially resistant to two races of Fusarium wilt. The G. hirsutum parent Acala NemX was susceptible to FOV1 and resistant to FOV4, whereas the G. barbadense parent Pima S7 was resistant to FOV1 and to susceptible FOV4. The results from QTL mapping analysis clearly revealed that the resistance to each race is complex, being determined by several independent loci in each case. Further, the resistance to each race showed no common major effect loci for resistance, with each being governed by 6 and 2 loci, respectively, located on separate chromosomes. However, major QTLs explained by the high percentage of the $F$. oxysporum $\mathrm{f}$. sp. vasinfectum variability reside in one or two chromosomes (FOV1, 12 and 16; and FOV4, 14 and 17), depending on the resistant/tolerant parent used to develop progeny. These results confirmed the race specificity of F. oxysporum $\mathrm{f}$. sp. vasinfectum, a condition typically associated with and delineated by major $\mathrm{R}$ genes. However, our findings revealed that in the race-host interactions analyzed here, the race specificity of the cotton response to each race is polygenically controlled. This polygenic race specificity is uncommon if not unique among reported plant pathosystems, being revealed by QTL mapping in a host population segregating for resistance to multiple pathogen races. The Puccinia graminis rust-Hordeum vulgare (barley) interaction has been reported to show polygenic race specificity, although that pathosystem apparently involves a poor-host status interaction but with evidence of some polygenic race specificity involved in partial resistance (Dracatos et al. 2016; Parlevliet and Van Ommeren 1985). Here, we emphasize the novelty of the polygenic race specificity found in the F. oxysporum f. sp. vasinfectum-cotton pathosystem, which is clearly based on resistant (host)-race (isolate) differential interactions in a good host-pathogen relationship. The underlying mechanisms at the gene level are unknown.

TABLE 1. Major effect quantitative trait loci (QTL) associated with Fusarium oxysporum f. sp. vasinfectum race 1 (FOV1) resistance

\begin{tabular}{|c|c|c|c|c|c|c|c|c|c|c|}
\hline \multicolumn{3}{|c|}{ FOV1 } & \multicolumn{4}{|c|}{ AUDPS } & \multicolumn{4}{|c|}{ VDL/PH } \\
\hline Chr & Position (cM) & Locus & $\mathrm{K}^{*}$ & Sig. & LOD & $\% \mathrm{PVE}$ & $\mathrm{K}^{*}$ & Sig. & LOD & $\%$ PVE \\
\hline $1 \mathrm{~B}$ & 7.813 & NAU3901-253/256 & 8.57 & $* * * *$ & 2.09 & 10.2 & & & & \\
\hline $2 B$ & 11.311 & JESPR156-0/115 & 8.17 & $* * * *$ & 1.75 & 8.0 & & & & \\
\hline 12 & 23.737 & Gh243-124/144 & 11.56 & $* * * * *$ & 1.97 & 9.8 & & & & \\
\hline 12 & 42.221 & HAU1434-329/300 & 14.53 & $* * * * * *$ & 3.20 & 15.2 & 8.19 & $* * * *$ & 1.65 & 8.2 \\
\hline 12 & 48.718 & DPL280-232/234 & 8.90 & $* * * *$ & 2.04 & 10.2 & & & & \\
\hline $15 \mathrm{~A}$ & 19.696 & NAU3901-276/244 & 8.50 & $* * * *$ & 2.55 & 12.5 & & & & \\
\hline $15 B$ & 22.992 & NAU4073-193/185 & 9.76 & $* * * *$ & 1.40 & 7.3 & 9.40 & $* * * *$ & 1.74 & 9.6 \\
\hline $21 \mathrm{~A}$ & 6.660 & CIR069-264/274 & 8.05 & $* * * *$ & 1.62 & 8.1 & & & & \\
\hline $21 \mathrm{~A}$ & 8.002 & UCR108-189/170 & 8.32 & $* * * *$ & 1.38 & 6.9 & & & & \\
\hline
\end{tabular}

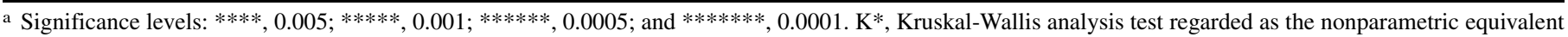
of the one-way analysis of variance. Chr, chromosome. VDL/PH\%, length of vascular discoloration/plant height $\times 100 \%$; LOD score and percentage $(\%)$ of phenotypic variance (PVE) are based on interval mapping analysis. For AUDPS (the area under the disease progress stairs), all evaluation data were combined into a single value. Significant (major) QTLs were set with a more stringent $P<0.005$ for Kruskal-Wallis. The genome-wide threshold value of LOD score after 1,000 permutation test for all traits at alpha $=0.05$ are 3.2 for both FOV1 AUDPS and VDL/PH.

TABLE 2. Major effect quantitative trait loci (QTL) associated with Fusarium oxysporum f. sp. vasinfectum race 4 (FOV4) resistance ${ }^{\text {a }}$

\begin{tabular}{|c|c|c|c|c|c|c|c|c|c|c|}
\hline \multicolumn{3}{|c|}{ FOV4 } & \multicolumn{4}{|c|}{ AUDPS } & \multicolumn{4}{|c|}{ VDL/PH } \\
\hline Chr & Position (cM) & Locus & $\mathrm{K}^{*}$ & Sig. & LOD & $\%$ PVE & $\mathrm{K}^{*}$ & Sig. & LOD & $\% \mathrm{PVE}$ \\
\hline 14B & 0.000 & BNL3932-246/255 & 8.642 & $* * * *$ & 2.32 & 11.2 & 7.28 & $* * *$ & 2.07 & 10.1 \\
\hline 14B & 1.167 & DPL0473-207/235 & 8.853 & $* * * * *$ & 2.35 & 11.5 & 7.35 & $* * *$ & 2.08 & 10.8 \\
\hline 17 & 15.128 & HAU1264-193/191 & 10.50 & $* * * *$ & 1.39 & 6.8 & 10.30 & $* * * *$ & 2.36 & 11.4 \\
\hline 17 & 15.197 & CIR180-234/238 & 9.86 & $* * * *$ & 1.39 & 6.9 & 10.31 & $* * * *$ & 2.36 & 11.4 \\
\hline 17 & 16.030 & BNL0834-161/165 & 9.50 & $* * * *$ & 1.41 & 6.9 & 11.06 & $* * * * *$ & 2.44 & 11.7 \\
\hline 17 & 24.046 & NAU3292-232/0 & 18.07 & $* * * * * * *$ & 3.88 & 18.1 & 18.53 & $* * * * * * *$ & 4.68 & 21.4 \\
\hline 17 & 29.341 & JESPR304-151/0 & 28.71 & $* * * * * * *$ & 7.36 & 31.4 & 27.75 & $* * * * * * *$ & 7.70 & 32.6 \\
\hline 17 & 30.606 & BNL2650-0/196 & 30.22 & $* * * * * * *$ & 7.91 & 33.3 & 26.93 & $* * * * * * *$ & 7.45 & 31.7 \\
\hline 17 & 30.606 & CIR112-0/226 & 30.22 & $* * * * * * *$ & 7.91 & 33.3 & 26.93 & $* * * * * * *$ & 7.45 & 31.7 \\
\hline 17 & 31.471 & CGR5453-145/115 & 26.44 & $* * * * * * *$ & 6.98 & 30.1 & 22.64 & $* * * * * * *$ & 6.42 & 28.0 \\
\hline
\end{tabular}

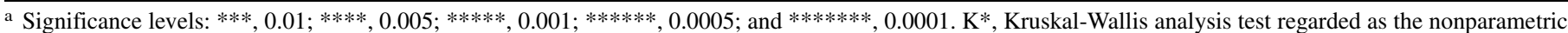
equivalent of the one-way analysis of variance based on single marker analysis. Chr, chromosome. VDL/PH, length of vascular discoloration/plant height $\times$ $100 \%$. LOD score and percentage (\%) of phenotypic variance (PVE) are based on interval mapping analysis. AUDPS indicates the area under the disease progress stairs which combined all evaluation data into a single value. Significant (major) QTLs were set with a more stringent $P<0.005$ for Kruskal-Wallis. The genome-wide threshold value of LOD score after 1,000 permutation test for all traits at alpha $=0.05$ are 3.2 for both FOV1 AUDPS and VDL/PH. 
The QTL analysis revealed gene interactions from both parents as a major component of resistance to both FOV1 and FOV4 (Table 3). For each F. oxysporum f. sp. vasinfectum race resistance, additional distinct minor effect QTLs were also identified, which contributed small phenotypic effects and are likely involved in epistatic gene interactions with each other and with the larger effect QTLs. As a guide to the relationship of the new QTLs identified here with those reported from other cotton backgrounds in our earlier studies (Ulloa et al. 2011, 2013), a comparison of QTLs involved in FOV1 and FOV4 resistance is presented in Table 3. We have not found any obvious relationships of the QTLs identified here colocating in genome regions of R-gene clusters in the cotton genome. The most obvious $\mathrm{R}$ gene clustering occurs on Chr 11, encompassing resistance to several pathogens and nematodes, as described in the introduction, and which includes FOV1 resistance QTLs mapped from other sources. However, the QTLs for F. oxysporum f. sp. vasinfectum resistance identified here do not localize to Chr 11. Here we discuss the comparisons for resistance to the two $F$. oxysporum f. sp. vasinfectum races.

For FOV1 resistance, our results indicated that the QTL Fov1C15 2 on Chr 15B from Pima 3-79 and Pima S-7 (Ulloa et al. 2011, 2013) has a shared location. The other five major QTLs (Fov1-C1, Fov1-C2 ${ }_{1}$,Fov1-C12, Fov1-C15, and Fov1-C21) in Pima S-7 or NemX found in the current study were not identified by Ulloa et al. $(2011,2013)$ in the P3-79 $\times$ TM-1 RIL population and therefore represent important novel QTLs as targets for selection. The QTL (Fov1-C21) region linked to CIR069 on Chr 21 was homoelogous with the root-knot nematode resistance gene rknl region on Chr 11 (Wang et al. 2006, 2015) and is also identified as a novel resistance locus. Interestingly, two alleles of the marker NAU3901 from the parent line Acala NemX were mapped to Chr 1 (Fov 1-C1 $\left.{ }_{1}\right)$ and Chr 15 (Fov1-C15 $)$, whereas a third allele of marker NAU3901 from P3-79 was mapped previously to Chr 15 (Ulloa et al. 2011).

The marker MUCS616 was found linked to FOV1 resistance in both RIL populations P3-79 $\times$ TM-1 (Ulloa et al. 2011) and in the present study in Pima S-7 $\times$ Acala NemX. To our surprise, the major QTL linked to the marker MUCS616 contributed up to $37 \%$ variance for FOV1 resistance in RIL population P3-79 $\times$ TM-1 and $6 \%$ variance in the $\mathrm{F}_{2}$ (Pima S-7 $\times$ Acala NemX) (Ulloa et al. 2011), yet the marker MUCS616 only produced minor effect $(P<0.1)$ in the RIL population Pima S-7 $\times$ Acala NemX, indicating that different genetic backgrounds affect gene expression, likely due to epistatic interactions. Another marker, MUSB0780 was identified to be linked to FOV1 resistance in both RIL populations. These comparisons of FOV1 resistance QTLs in summary reveal a combination of novel QTLs identified in the new RIL population, and also provide validation of previously identified QTLs found in other interspecific RIL populations. Further, the same QTLs contribute different levels of resistance phenotype depending on the genetic background.

For FOV4 resistance, a previous report (Ulloa et al. 2013) clearly stated the complexity of recombination and duplicated marker-loci between Chr 17 and homeologous Chr 14 (Yu et al. 2011, 2012) and the importance of major genome regions in determining resistance to FOV4 on these chromosomes. Here we mapped a major locus, Fov4-C17, linked to SSR markers BNL2650 and CIR112 on Chr 17 and which contributed up to $33 \%$ phenotypic variance for FOV4 resistance. The marker BNL0834 was mapped to Chr 17 (Fig. 5) and Chr 2 (Fig. 4) in the present study and to Chr 14 previously (Ulloa

TABLE 3. Comparison of loci involved in Fusarium oxysporum f. sp. vasinfectum race 1 (FOV1) and race 4 (FOV4) resistance in $\mathrm{F}_{2: 8}$ Pima S-7 $\times$ NemX with quantitative trait loci (QTL) from Pima 3-79 (P3-79) $\times$ TM1 or Pima S6 (PS6) ${ }^{\mathrm{a}}$

\begin{tabular}{lllllll}
\hline & FOV1 & FOV1 & FOV4 & FOV4 & FOV1 P3-79 $\times$ TM1 & FOV4 P3-79 $\times$ TM1 or \\
Chr & Pima S-7 & NemX & Pima S-7 & NemX & (Ulloa et al. 2011, 2016) & PS6 (Ulloa et al. 2013) \\
\hline 1A & + NAU5100 & Fov1-C1 (NAU3901) & & +NAU3922 & TM-1 (MUCS164) \\
1B & & +NAU5111 & & & \\
2A & & & &
\end{tabular}

+MUSB0780

12 Fov1-C12 (HAU1434)

$14 \mathrm{~A}$

$14 \mathrm{~B}$

$\begin{array}{ll}\text { 15A } & \\ 15 \mathrm{~B} & \text { Fov1-C15, (NAU4073) } \\ & \\ 16 & +\mathrm{MUCS} 616 \\ 17 & +\mathrm{NAU} 3955 \\ & \\ 19 & \\ 21 \mathrm{~A} & \text { Fov1-C21 (CIR069) } \\ 21 \mathrm{~B} & \\ 23 & \\ 24 & \\ 25 & +\mathrm{Gh} 295\end{array}$

$\begin{array}{ll} & \\ & \\ & +\mathrm{MUSB} 0404 \\ & +\mathrm{Gh} 243 \\ & \\ & \end{array}$

Gh262

$\begin{array}{ll}\text { +HAU2583 } & \text { P3-79 (MUSB0780) }\end{array}$

Fov4-C14 2 (MUSB0850, BNL3932)

$\begin{array}{r}\text { Fov1-C15, } \\ \text { (NAU3901) }\end{array}$
+NAU5273
+MUSB810

+NAU4045

\section{Fov4-C17 (BNL2650 CIR112)}

$+\mathrm{DC} 40316$

+NAU3265

$+\mathrm{BNL} 1672$

+ CIR061

+NAU4969, Gh537
P3-79 (MUSB0155)

P3-79 (MUSB0117)

P3-79 (BNL226)

PS6 (MUSB0639)

PS6 (NAU2714)

TM-1 (MUSB0780)

PS6 (MUSB0780)

\author{
TM-1 (BNL0834) \\ PS6 (BNL0834) \\ Colocation with \\ Fov4-C14,
}

P3-79 (NAU3901)

P3-79 (MUSS128)

Colocation with Fov1-C15, P3-79 (MUCS616)

P3-79 (JESPR304)

P3-79 (Gh109)

PS6 (BNL2496)

TM-1 (JESPR224)

PS6 (NAU2714)

Colocation with Gh537

$26+$ HAU1434

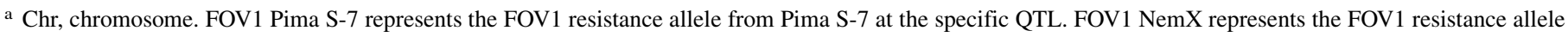
from NemX at the specific QTL. The equivalent notation applies to FOV4. +NAU5100 indicates minor QTL with associated markers. Major QTLs display names and the linked markers are highlighted in bold black. TM-1 (MUCS164) indicates a FOV1 resistance QTL (corresponding column) associated with the marker MUCS164 at the chromosome 1A region (corresponding row) from TM-1. The same notation applies for other designations in the last two columns. 
et al. 2013; Yu et al. 2012). The QTL Fov4-14 2 for FOV4 resistance from Acala NemX identified here showed the same location with the major resistance QTL linked to BNL0834 which mapped to Chr 14 from TM-1 (Ulloa et al. 2013).

The marker JESPR304 mapped to Chr 17 and Chr 2 (Figs. 4 and 5 ), which confirmed our previous mapping of these loci using chromosome substitution lines of G. barbadense P3-79 substituted into G. hirsutum TM1 (Ulloa et al. 2016). The marker JESPR304 was also mapped to Chr 17 linked to FOV7 resistance in Chinese Upland (G. hirsutum) cotton (Wang et al. 2009), with four QTLs detected under different conditions in the same region (Wang et al. 2010b). Mei et al. (2014) also reported marker BNL0834 on Chr 17 to be associated with FOV7 resistance. As introduced earlier, molecular diagnostic analysis for race identification could not distinguish between race 4 and race 7 (Cianchetta and Davis 2015; Skovgaard et al. 2001; Wang et al. 2010a), and their common control by resistance QTLs on Chr 14 and Chr 17 support that they are very similar pathogenically.

The genomic organization of homeologous regions of $\mathrm{Chr} 2$, Chr 14, and Chr 17 in which FOV4 resistance is localized may provide the basis for the variable extent of resistance contribution found in different genetic backgrounds and segregating populations. Interestingly, the markers BNL2650 and CIR112, which are close to the major FOV4 resistance locus on Chr 17, were also mapped with different alleles to the telomeric regions of both Chr 11 and $\mathrm{Chr} 21$, regions which were associated with root-knot nematode resistance, Fusarium wilt resistance, and reniform nematode resistance (Fig. 5; Table 3) (Wang et al. 2015, 2017). Both Chr 8 and Chr 24 were identified to be associated with FOV7 resistance (Mei et al. 2014). In addition, a QTL on Chr 25 associated with FOV4 resistance in TM-1 or Pima S-6 (Ulloa et al. 2013) was found to colocate with minor QTLs in Acala NemX (Table 3). Again, these data suggest that complex genome recombination patterns result in new genotypes.

The availability of diploid $\mathrm{A}\left(G\right.$. arboreum $\left.\mathrm{A}_{2}\right)$ and $\mathrm{D}(G$. raimondii $\mathrm{D}_{5}$ ) and domesticated tetraploid AD (TM-1, G. hirsutum) whole genome sequences (Li et al. 2014, 2015; Paterson et al. 2012; Wang et al. 2012b; Zhang et al. 2015b) will be useful in fine mapping these QTLs associated with Fusarium wilt resistance for molecularassisted selection in cotton breeding programs. In addition, some $\mathrm{F}_{8}$ lines from the new Pima S7 $\times$ Acala NemX RIL population used here have resistance to root-knot nematode (Wang et al. 2017) combined with resistance to both FOV1 and FOV4. These advanced multiple resistance lines are excellent donors for cotton breeding programs at a time when cotton losses due to nematode and Fusarium wilt infections are increasing.

\section{LITERATURE CITED}

Abawi, G. S., and Chen, J. 1998. Concomitant pathogen and pest interactions. Pages 135-138 in: Plant and Nematode Interactions. Am. Soc. Agro., Crop Sci. Soc. Am., Soil Sci. Soc. Am., Madison, WI.

Armstrong, G. M., and Armstrong, J. K. 1960. American, Egyptian, and Indian cotton-wilt Fusaria: Their pathogenicity and relationship to other wilt fusaria. U.S. Dep. Agric. Tech. Bull. 219.

Baker, K. F. 1957. The U.C. system for producing healthy container-grown plants. Calif. Agric. Exp. Stn. Man. 23:1-332.

Bolek, Y., El-Zik, K. M., Pepper, A. E., Bell, A. A., Magill, C. W., Thaxton, P. M., and Reddy, O. U. K. 2005. Mapping of Verticillium wilt resistance gens in cotton. Plant Sci. 168:1581-1590.

Churchill, G. A., and Doerge, R. W. 1994. Empirical threshold values for quantitative traits mapping. Genetics 138:963-971.

Cianchetta, A. N., and Davis, R. M. 2015. Fusarium wilt of cotton: Management strategies. Crop Prot. 73:40-44.

Crutcher, F. K., Doan, H. K., Bell, A. A., Davis, M. R., Stipanovic, R. D., Nichols, R. L., and Liu, J. 2016. Evaluation of methods to detect the cotton wilt pathogen Fusarium oxysporum f. sp. vasinfectum race 4. Eur. J. Plant Pathol. 144:225-230.

Davis, R. D., Moore, N. Y., and Kochman, J. K. 1996. Characterization of a population of Fusarium oxysporum f. sp. vasinfectum causing wilt of cotton in Australia. Aust. J. Agric. Res. 47:1143-1156.
Dighe, N. D., Robinson, A. F., Bell, A. A., Menz, M. A., Cantrell, R. G., and Stelly, D. M. 2009. Linkage mapping of resistance to reniform nematode in cotton following introgression from Gossypium longicalyx (Hutch. \& Lee). Crop Sci. 49:1151-1164.

Dracatos, P. M., Nansamba, M., Berlin, A., Park, R. F., and Niks, R. E. 2016. Isolate specificity and polygenic inheritance of resistance in barley to the heterologous rust pathogen Puccinia graminis f. sp. avenae. Phytopathology 106:1029-1037.

Garber, R. H., Jorgenson, E. C., Smith, S., and Hyer, A. H. 1979. Interaction of population levels of Fusarium oxysporum f. sp. vasinfectum and Meloidogyne incognita on cotton. J. Nematol. 11:133-137.

Gutiérrez, O. A., Jenkins, J. N., Wubben, M. J., Hayes, R. W., and Callahan, F. E. 2010. SSR markers closely associated with genes for resistance to root-knot nematode on chromosomes 11 and 14 of Upland cotton. Theor. Appl. Genet. 121:1323-1337.

Gutiérrez, O. A., Robinson, A. F., Jenkins, J. N., McCarty, J. C., and Wubben, M. J. 2011. Identification of QTL regions and SSR markers associated with resistance to reniform nematode in Gossypium barbadense L. accession GB713. Theor. Appl. Genet. 122:271-280.

Hao, J. J., Yang, M. E., and Davis, M. R. 2009. Effect of soil inoculum density of Fusarium oxysporum f. sp. vasinfectum race 4 on disease development in cotton. Plant Dis. 93:1324-1328.

Hutmacher, B., Ulloa, M., Wright, S. D., Campbell, T. B., Percy, R., Wallace, T., Myers, G., Nourland, F., Weaver, D., Chee, P., Thaxton, P., Zhang, J., Smith, W., Dever, J., Kuraparthy, V., Bowman, D., Jones, D., and Burke, J. 2013. Elite Upland cotton germplasm-pool assessment of Fusarium wilt resistance in California. Agron. J. 105:1635-1644.

Kim, Y., Hutmacher, R. B., and Davis, R. M. 2005. Characterization of California isolates of Fusarium oxysporum f. sp. vasinfectum. Plant Dis. 89: 366-372.

Li, F., Fan, G., Lu, C., Xiao, G., Zou, C., Kohel, R. J., Ma, Z., Shang, H., Ma, X., Wu, J., Liang, X., Huang, G., Percy, R. G., Liu, K., Yang, W., Chen, W., Du, X., Shi, C., Yuan, Y., Ye, W., Liu, X., Zhang, X., Liu, W., Wei, H., Wei, S., Huang, G., Zhang, X., Zhu, S., Zhang, H., Sun, F., Wang, X., Liang, J., Wang, J., He, Q., Huang, L., Wang, J., Cui, J., Song, G., Wang, K., Xu, X., Yu, J. Z., Zhu, Y., and Yu, S. 2015. Genome sequence of cultivated Upland cotton (Gossypium hirsutum TM-1) provides insights into genome evolution. Nat. Biotechnol. 33:524-530.

Li, F., Fan, G., Wang, K., Sun, F., Yuan, Y., Song, G., Li, Q., Ma, Z., Lu, C., Zou, C., Chen, W., Liang, X., Shang, H., Liu, W., Shi, C., Xiao, G., Gou, C., Ye, W., Xu, X., Zhang, X., Wei, H., Li, Z., Zhang, G., Wang, J., Liu, K., Kohel, R. J., Percy, R. G., Yu, J. Z., Zhu, Y. X., Wang, J., and Yu, S. 2014. Genome sequence of the cultivated cotton Gossypium arboreum. Nat. Genet. 46:567-572.

Lopez-Lavalle, A. B. L., Gillespie, V. J., Tate, W. A., Ellis, M. H., Stiller, W. N., Llewellyn, D. L., and Wilson, I. W. 2012. Molecular mapping of a new source of Fusarium wilt resistance in tetraploid cotton (Gossypium hirsutum L.). Mol. Breed. 30:1181-1191.

Lopez-Lavalle, A. B. L., McFadden, H., and Brubaker, C. L. 2007. The effect of Gossypium C-genome chromosomes on resistance to Fusarium wilt in allotetraploid cotton. Theor. Appl. Genet. 115:477-488.

Mei, H., Ai, N., Zhang, X., Ning, Z., and Zhang, T. 2014. QTLs conferring FOV7 resistance detected by linkage and association mapping in Upland cotton. Euphytica 197:237-249.

Niu, C., Lister, H. E., Nguyen, B., Wheeler, T. A., and Wright, R. J. 2008. Resistance to Thielaviopsis basicola in the cultivated A genome cotton. Theor. Appl. Genet. 117:1313-1323.

Ortiz, C. S., Bell, A. A., Magill, C. W., and Liu, J. 2017. Specific PCR detection of Fusarium oxysporum f. sp. vasinfectum California race 4 based on a unique Tfol insertion event in the PHO gene. Plant Dis. 101: 34-44.

Parlevliet, J. E., and Van Ommeren, A. 1985. Race-specific effects in major genic and polygenic resistance of barley to barley leaf rust in the field: Identification and distinction. Euphytica 34:689-695.

Paterson, A. H., Wendel, J. F., Gundlach, H., Guo, H., Jenkins, J., Jin, D., Llewellyn, D., Showmaker, K. C., Shu, S., Udall, J., Yoo, M. J., Byers, R., Chen, W., Doron-Faigenboim, A., Duke, M. V., Gong, L., Grimwood, J., Grover, C., Grupp, K., Hu, G., Lee, T. H., Li, J., Lin, L., Liu, T., Marler, B. S., Page, J. T., Roberts, A. W., Romanel, E., Sanders, W. S., Szadkowski, E., Tan, X., Tang, H., Xu, C., Wang, J., Wang, Z., Zhang, D., Zhang, L., Ashrafi, H., Bedon, F., Bowers, J. E., Brubaker, C. L., Chee, P. W., Das, S., Gingle, A. R., Haigler, C. H., Harker, D., Hoffmann, L. V., Hovav, R., Jones, D. C., Lemke, C., and Mansoor, S., Rahman, M., Rainville, L. N., Rambani, A., Reddy, U. K., Rong, J. K., Saranga, Y., Scheffler, B. E., Scheffler, J. A., Stelly, D. M., Triplett, B. A., Van Deynze, A., Vaslin, M. F., Waghmare, V. N., Walford, S. A., Wright, R. J., Zaki, E. A., Zhang, T., Dennis, E. S., Mayer, K. F., Peterson, D. G., Rokhsar, D. S., Wang, X., and Schmutz, J. 2012. Repeated polyploidization of Gossypium genomes and the evolution of spinnable cotton fibers. Nature 492:423-427. 
Shen, X., Van Becelaere, G., Kumar, P., Davis, R. F., May, L. O., and Chee, P. 2006. QTL mapping for resistance to root-knot nematodes in the M-120 RNR Upland cotton line (Gossypium hirsutum L.) of the Auburn 623 RNR source. Theor. Appl. Genet. 113:1539-1549.

Shi, Y., Zhang, B., Liu, A., Li, W., Li, J., Lu, Q., Zhang, Z., Li, S., Gong, W., Shang, H., Gong, J., Chen, T., Ge, Q., Wang, T., Zhu, H., Liu, Z., and Yuan, Y. 2016. Quantitative trait loci analysis of Verticillium wilt resistance in interspecific backcross populations of Gossypium hirsutum $\times$ Gossypium barbadense. BMC Genomics 17:877.

Simko, I., and Piepho, H. P. 2012. The area under the disease progress stairs: Calculation, advantage, and application. Phytopathology 102:381-389.

Skovgaard, K., Nirenberg, H. I., O'Donnell, K., and Rosendahl, S. 2001. Evolution of Fusarium oxysporum f. sp. vasinfectum races inferred from multigene genealogies. Phytopathology 91:1231-1237.

Smith, S. N., Jeffers, D. P., and DeVay, J. E. 1994. Effects of glucose and biotin on the growth and sporulation of Fusarium species, especially pathogenic and nonpathogenic isolates of Fusarium oxysporum. Mycologia 86:547-554.

Ulloa, M., Hutmacher, R. B., Davis, R. M., Wright, S. D., Percy, R., and Marsh, B. 2006. Breeding for Fusarium wilt race 4 resistance in cotton under field and greenhouse conditions. J. Cotton Sci. 10:114-127.

Ulloa, M., Hutmacher, R. B., Roberts, P. A., Wright, S. D., Nichols, R. L., and Michael, D. R. 2013. Inheritance and QTL mapping of Fusarium wilt race 4 resistance in cotton. Theor. Appl. Genet. 126:1405-1418.

Ulloa, M., Wang, C., Hutmacher, R. B., Wright, S. D., Davis, R. M., Saski, C. A., and Roberts, P. A. 2011. Mapping Fusarium wilt race 1 genes in cotton by inheritance, QTL and sequencing composition. Mol. Genet. Genomics 286:21-36.

Ulloa, M., Wang, C., and Roberts, P. A. 2010. Gene action analysis by inheritance and quantitative trait loci mapping of resistance to root-knot nematodes in cotton. Plant Breed. 129:541-550.

Ulloa, M., Wang, C., Saha, S., Hutmacher, R. B., Stelly, D. M., Jenkins, J. N., Burke, J., and Roberts, P. A. 2016. Analysis of root-knot nematode and fusarium wilt disease resistance in cotton (Gossypium spp.) using chromosome substitution lines from two alien species. Genetica 144:167-179.

Van Ooijen, J. W. 2004. MapQTL 5, Software for the mapping of quantitative trait loci in experimental populations. Kyazma B.V., Wageningen, Netherlands.

Van Ooijen, J. W. 2006. JoinMap 4.0 Software for the calculations of genetic linkage maps in experimental populations. Kyazma B.V., Wageningen, Netherlands.

Wang, B., Brubaker, C. L., Summerell, B. A., Thrall, P. H., and Burdon, J. J. 2010a. Local origin of two vegetative compatibility groups of Fusarium oxysporum f. sp. vasinfectum in Australia. Evol. Appl. 3:505-524.

Wang, C., and Roberts, P. A. 2006. A Fusarium wilt resistance gene in Gossypium barbadense and its effect on root-knot nematode-wilt disease complex. Phytopathology 96:727-734.

Wang, C., Ulloa, M., Duong, T. T., and Roberts, P. A. 2017. QTL analysis of transgressive nematode resistance in tetraploid cotton reveals complex interactions in chromosome 11 regions. Front. Plant Sci. 8:1979.

Wang, C., Ulloa, M., Mullens, T. R., Yu, J. Z., and Roberts, P. A. 2012a. QTL analysis for transgressive resistance to root-knot nematode in interspecific cotton (Gossypium spp.) progeny derived from susceptible parents. PLoS One $7:$ e34874

Wang, C., Ulloa, M., and Roberts, P. A. 2006. Identification and mapping of microsatellite markers linked to a root-knot nematode resistance gene (rkn1) in Acala NemX cotton (Gossypium hirsutum L.). Theor. Appl. Genet. 112:770-777.

Wang, C., Ulloa, M., and Roberts, P. A. 2008. A transgressive segregation factor (RKN2) in Gossypium barbadense for nematode resistance clusters with gene rkn1 in G. hirsutum. Mol. Gen. Genomics 279:41-52.

Wang, C., Ulloa, M., Shi, X., Yuan, X., Saski, C., Yu, J. Z., and Roberts, P. A. 2015. Sequence composition of BAC clones and SSR markers mapped to Upland cotton chromosomes 11 and 21 targeting resistance to soil-borne pathogens. Front. Plant Sci. 6:791

Wang, K., Wang, Z., Li, F., Ye, W., Wang, J., Song, G., Yue, Z., Cong, L., Shang, H., Zhu, S., Zou, C., Li, Q., Yuan, Y., Lu, C., Wei, H., Gou, C., Zheng, Z., Yin, Y., Zhang, X., Liu, K., Wang, B., Song, C., Shi, N., Kohel, R. J., Percy, R. G., Yu, J. Z., Zhu, Y. X., and Yu, S. 2012b. The draft genome of a diploid cotton Gossypium raimondii. Nat. Genet. 44:1098-1103.

Wang, P., Shi, L., Su, L., and Hu, B. 2010b. Quantitative trait loci for resistance against Fusarium wilt based on three cotton $\mathrm{F}_{2}$ populations. Agric. Sci. China 9:1799-1806.

Wang, P., Su, L., Qin, L., Hu, B., Guo, W., and Zhang, T. 2009. Identification and molecular mapping of Fusarium wilt resistant gene in upland cotton. Theor. Appl. Genet. 119:733-739.

Wei, H., Li, W., Sun, X., Zhu, S., and Zhu, J. 2013. Systematic analysis and comparison of nucleotide-binding site disease resistance genes in a diploid cotton Gossypium raimondii. PLoS One 8:e68435.

Ynturi, P., Jenkins, J. N., McCarty, J. C., Jr., Gutiérrez, O. A., and Saha, S. 2006. Association of root-knot nematode resistance genes with simple sequence repeat markers on two chromosomes in cotton. Crop Sci. 46:2670-2674.

Yu, J., Kohel, R. J., Fang, D. D., Cho, J., Van Deynze, A., Ulloa, M., Hoffman, S. M., Pepper, A. E., Stelly, D. M., Jenkins, J. N., Saha, S., Kumpatla, S. P., Shah, M. R., Hugie, W. V., and Percy, R. G. 2012. A high-density simple sequence repeat and single nucleotide polymorphism genetic map of the tetraploid cotton genome. G3 (Bethesda) 2:43-58.

Yu, Y., Yuan, D., Liang, S., Li, X., Wang, X., Lin, Z., and Zhang, X. 2011. Genome structure of cotton revealed by a genome-wide SSR genetic map constructed from a $\mathrm{BC} 1$ population between Gossypium hirsutum and G. barbadense. BMC Genomics 12:15.

Zhang, J. F., Sanogo, S., Ma, Z. Y., and Qu, Y. Y. 2015a. Breeding, genetics, and quantitative trait locus mapping for Fusarium wilt resistance in cotton. Crop Sci. 55:2435-2452.

Zhang, T., Hu, Y., Jiang, W., Fang, L., Guan, X., Chen, J., Zhang, J., Saski, C. A., Scheffler, B. E., Stelly, D. M., Hulse-Kemp, A. M., Wan, Q., Liu, B., Liu, C., Wang, S., Pan, M., Wang, Y., Wang, D., Ye, W., Chang, L., Zhang, W., Song, Q., Kirkbride, R. C., Chen, X., Dennis, E., Llewellyn, D. J., Peterson, D. G., Thaxton, P., Jones, D. C., Wang, Q., Xu, X., Zhang, H., Wu, H., Zhou, L., Mei, G., Chen, S., Tian, Y., Xiang, D., Li, X., Ding, J., Zuo, Q., Tao, L., Liu, Y., Li, J., Lin, Y., Hui, Y., Cao, Z., Cai, C., Zhu, X., Jiang, Z., Zhou, B., Guo, W., Li, R., and Chen, Z. J. 2015b. Sequencing of allotetraploid cotton (Gossypium hirsutum L. acc. TM-1) provides a resource for fiber improvement. Nat. Biotechnol. 33:531-537. 